\title{
A Psicanálise e suas clínicas: avanços e aberturas ${ }^{1}$
}

\author{
Ana Paula Terra Machado²
}

Clinicar é enfrentar cotidianamente os desafios que o encontro com o outro nos impõe. A clínica é a psicanálise encarnada. É onde se verifica a potência do método e onde se criam novas teorias. A clínica é o seu maior valor e o que lhe confere a sua fundamental importância, desde o seu surgimento até hoje.

Foram os fenômenos clínicos que deram origem à psicanálise, e esta premissa segue com sua validade e pertinência. Os impasses surgidos na clínica impuseram novas formas de abordagem e novos desdobramentos teóricos. As teorias nos auxiliam na compreensão da experiência emocional de cada caso. Porém, sabemos que nenhuma teoria alcança a complexidade do humano.

A psicanálise "acha-se sempre incompleta e sempre pronta a corrigir ou modificar suas teorias. Não há incongruência se a seus conceitos mais gerais falta clareza, e seus postulados são provisórios; ela deixa a definição mais precisa deles aos resultados do trabalho futuro" (Freud, 1923, p. 307).

Trabalhar na clínica é, acima de tudo, acolher a dor do outro. Esta receptividade já pressupõe, desde o início, uma ética da escuta e, por extensão, da fala. Refiro-me ao que o analista fala e interpreta, pois, diante do conteúdo verbalizado pelo analisando, é necessária a compreensão do timing, já que, simultaneamente à compreensão do material, é preciso que seja avaliada a possibilidade de escuta sobre o que será dito. Além de não gerar nenhuma reflexão, interpretações "profundas" podem produzir um efeito adverso para o processo analítico, embora saibamos que, entre aquilo que se fala e que o analisando escuta, pode haver uma grande distância.

\footnotetext{
${ }^{1}$ Este trabalho é a plenária do eixo "A psicanálise e suas clínicas”, apresentada no I Simpósio Bienal "O mesmo, o outro: Psicanálise em movimento" da Sociedade Brasileira de Psicanálise de São Paulo.

${ }^{2}$ Membro Titular da Sociedade Brasileira de Psicanálise de Porto Alegre - SBPdePA.
} 
A psicanálise contemporânea compreende diferentes áreas do funcionamento psíquico. Hoje, trabalhamos com pares que se tornaram indissociáveis - como pulsão/objeto e transferência/contratransferência - e com a articulação entre o intrapsíquico e o intersubjetivo, o que implica novas posições do analista. A extensão da clínica alargou os limites de analisabilidade, e o critério não é a psicopatologia, mas, sim, a possibilidade da dupla, analista-analisando, de empreender um processo analítico.

No que se refere à teoria, vivemos uma época do pós-escolas, e os autores contemporâneos, ainda que sigam tendências de uma escola, não desconhecem os postulados de outros autores; mais do que isso, eles incorporam os conhecimentos de outras correntes teóricas para ampliar suas hipóteses e construir novas teorias. Novos pressupostos teóricos são fundamentais para dar conta das dificuldades da clínica e para manter a vitalidade do nosso ofício. Isso é salutar e desejável para o desenvolvimento de nossa disciplina, ainda que não nos livre do risco de um ecletismo que suscite uma espécie de "vale tudo", de um aglomerado de ideias e conceitos carentes de consistência. "Somente os crentes que exigem que a ciência seja um substituto para o catecismo que abandonaram, culparão um investigador por desenvolver ou mesmo transformar suas concepções” (Freud, 1920, p. 85). Aferrar-se a uma teoria leva a dogmatismos que empobrecem a compreensão da multiplicidade de variáveis que o campo da psicanálise nos oferece.

É claro que, na compreensão de uma teoria e de um material clínico, surgem divergências, mas "as nossas diferenças mostram-nos todas as coisas que a psicanálise pode ser, mesmo que não possa ser tudo de uma só vez ou para qualquer pessoa" (Schafer, citado por Busch, 2015, p. 113).

Quando descrevemos um caso clínico e refletimos sobre a sua dinâmica à luz da teoria, é indispensável termos presente que sempre haverá uma distância entre a teoria e a clínica, o que não exclui a ideia de construirmos hipóteses que nos auxiliem a articular uma inteligibilidade entre a experiência emocional do par na sala de análise e os conceitos teóricos. Este modelo de compreensão segue os princípios estabelecidos por Freud para a construção do corpo teórico da psicanálise. 
A questão é como sustentar esta distância, esta brecha... Podemos conjecturar que é justamente neste espaço onde surge o pensamento clínico, como um produto das vivências da clínica com o conhecimento teórico. É o espaço onde o novo, o criativo e o singular de cada caso ganham seus contornos.

Considero que o pensamento clínico ocorre na sessão, no calor da sessão, quando são formuladas teorizações flutuantes, mas também a posteriori, quando o material é pensado, escrito e comunicado. É como um segundo momento, no qual podem ser avaliados o dispositivo analítico, sua eficácia e suas limitações. Desta forma, o pensamento clínico é o que permite que hipóteses sejam verificadas, validadas ou refutadas, ao longo do processo de análise. Ele é uma forma de cotejamento entre a prática e a teoria, mantendo sempre esse espaço no qual temos que tolerar algo de inapreensível. Trabalhamos sempre no território movediço do desconhecido a cada sessão.

Todo ser humano é uma obra aberta, e a cada sessão a clínica se renova.São os analisandos que determinam a clínica, ou seja, nada pode ser pensado a priori, e cada sessão é única. Por isso, nosso ofício é complexo, aproxima-se da arte, pressupõe intuição, sensibilidade e se entrecruza com todas as disciplinas do humano. Entretanto, é a clínica com seu permanente movimento que interpela a psicanálise, problematiza os conceitos e assegura a sua vigência.

Embora haja uma grande discussão em torno da questão sobre se o ouro da psicanálise é circunscrito a determinados critérios, considero que a ação terapêutica, mesmo em um setting diferente do clássico, é um trabalho de psicanálise. Refiro-me aqui ao debate sobre análise ou psicoterapia psicanalítica. A expansão do espectro de pessoas que procuram um psicanalista impõe que estas questões sejam revistas. Nem todas as análises podem ser empreendidas dentro um setting padrão, mas, apesar das modificações, em função da organização psíquica do paciente, ou ainda de outras variáveis que exijam alterações do setting, ainda assim penso que é psicanálise.

As regras permanecem, mas as combinações feitas com o analisando variam; estas variáveis, porém, paradoxalmente, precisam ser fixas e constantes. Se consideramos que o nosso objeto é o inconsciente e que nosso trabalho ocorre no campo dinâmico da 
transferência, estamos diante de um trabalho psicanalítico. "A extraordinária diversidade das constelações psíquicas envolvidas, a plasticidade de todos os processos mentais e a riqueza dos fatores determinantes opõem-se a qualquer mecanização das técnicas" (Freud, 1913, p. 164).

Sabemos que o mais importante é o enquadre interno do analista (Green, 2008), sua atitude mental, constituída através de sua análise pessoal, seu conhecimento teórico e de sua prática cotidiana. É na clínica que convergem todos os aspectos de uma formação.

Há ainda outros fatores que se inserem no setting, ainda que, muitas vezes, de forma sub-reptícia e inconsciente, como as questões da vida pessoal do analista, suas ideologias e seus preconceitos. Destaco este aspecto porque, no que se refere ao trabalho de um psicanalista, os preconceitos são um entrave à escuta. Se, socialmente, o preconceito é indesejado, na clínica ele se torna uma limitação da compreensão do analisando, pois estabelece um juízo de valor, o que é contrário aos fundamentos de nosso fazer clínico. O risco está em acharmos que estamos livres de preconceitos e ideologias. Somente admitindo sua existência é que podemos pensar sobre eles.

Contudo, também não podemos conceber a clínica como se esta fosse um lugar pasteurizado, imune às características individuais do analista. Ao contrário, a clínica é o lugar de um encontro, onde cada um dos participantes tem que ter uma presença viva. Cada analista precisa introjetar a teoria, trabalhar como se ela fosse sua e construir o seu estilo pessoal. Nada mais artificial e inautêntico que um analista opaco e sem expressão, que pretenda trabalhar com uma neutralidade asséptica.

Isto não quer dizer que se prescinda da abstinência, que considero fundamental para que um processo analítico ocorra. Nele, haverá um desalojar-se de si, possibilitando uma abertura ao outro. $\mathrm{O}$ analista precisa estar implicado no processo, ser afetado pela fala e pelo silêncio do analisando.

Esta abertura está para além da disponibilidade interna, do desejo de analisar ou, ainda, de se colocar sem memória e sem desejo. É uma abertura radical, de duplo vértice: para o estrangeiro dele mesmo, para as ressonâncias de seu inconsciente - o grande instrumento do trabalho clínico - e para o que vem do outro com a toda a carga 
pulsional que isto representa. Refiro-me aqui ao campo de forças no qual ocorre a análise, onde operam, para além das resistências, a destrutividade e os ataques ao pensamento. Cabe, então, ao analista suportar a força da transferência, o que é depositado nele, compreender e transformar em pensável o que ocorre na sessão.

Sabemos que o masoquismo erógeno é a primeira intrincação pulsional, onde ocorre a primeira ligação de Eros. Para Hartke $\left(2018^{3}\right)$, o que sustenta esta condição do analista de manter uma atitude mental receptiva, de tolerar as intensidades das projeções e de superar o cansaço de horas de trabalho é o "masoquismo erógeno do analista". O analista é o guardião do setting e, como tal, precisa manter a capacidade de seguir pensando, onde a carga pulsional desligada das representações se apresenta com o seu potencial destrutivo.

Embora o trabalho específico de um analista seja na sala de análise, e a nossa clínica seja a clínica da singularidade, a psicanálise transita simultaneamente entre o universal e o singular, entre o mesmo e o outro e, nesta perspectiva, nos reconhecemos e nos diferenciamos. São estes movimentos que nos permitem uma aproximação empática com o sofrimento e a distância necessária, para que se crie o campo de trabalho no qual a psicanálise ocorre.

São múltiplas as aplicações do método com suas particularidades em relação ao enquadre e à instrumentalização da técnica, mas a condição para o trabalho clínico é o sofrimento. Este sim é o grande indicador para que alguém seja atendido por um psicanalista, mesmo que alguns analisandos cheguem para a análise sem uma clareza de sua demanda. Muitas vezes, é preciso criar a demanda, e caberá, então, ao analista "colocar o tratamento no futuro analisando", segundo as palavras de Francischelli (2012, p. 57).

Esta condição se tornou ainda mais relevante diante dos pacientes da atualidade, que se caracterizam por uma dificuldade de expressão por meio de palavras e por uma pobreza

\footnotetext{
${ }^{3}$ Comentário de Raul Hartke na Reunião Científica da SPPA em maio de 2018, na apresentação do trabalho pré-publicado do Congresso da Fepal, "Masoquismo: destino das pulsões - origem do sujeito", de Ana Paula Terra Machado e Ignácio Alves Paim Filho.
} 
simbólica que impõe descargas no corpo e na ação. Por outro lado, porém, há pacientes que apresentam o oposto de uma via de descarga na ação, ou mesmo no corpo, e se situam no outro limite deste espectro. Refiro-me às inibições severas, que se caracterizam por uma paralisia da ação, de uma imobilidade que gera impedimentos para se levar adiante as tarefas da vida, onde toda a ação parece ser ameaçadora.

A psicopatologia atual compreende os estados precoces do desenvolvimento, que envolvem defesas mais radicais e formações do inconsciente que não dizem respeito a conteúdos recalcados. Esta condição envolve os déficits dos períodos da constituição do psiquismo. As vivências infantis destes primeiros tempos serão constitutivas do sujeito e determinarão como se dará a circulação dos afetos e a representação do corpo, bem como se instalará a confiança na vida.

Embora nosso trabalho ocorra a partir do que é verbalizado pelo analisando, nossa escuta tem que ser ampla e transcender à palavra. Temos que ouvir o que está além e aquém das palavras. O paraverbal, o não verbal e as expressões do corpo são formas de comunicação que exigem que a mente do analista esteja disponível, para que o que não dito possa ser pensado, imaginado e historicizado. Para determinados pacientes, poder falar de si, relatar sua história e fazer uso da associação livre não é o ponto de partida, mas sim o ponto de chegada, uma conquista da análise.

Há casos nos quais o silêncio nas sessões é uma tônica dos atendimentos exigindo uma participação mais ativa do analista, para que se instaure e se mantenha um processo analítico. São situações onde o ritmo das sessões pode ser paralisado por uma resistência persistente que põe em risco a própria continuidade da análise. Nestas circunstâncias, é ainda mais importante que o analista use a sua capacidade de imaginar, de pensar sobre o que não pode ser verbalizado.

Precisamos criar condições, para que o paciente tolere o processo analítico. Temos que poder suportar o tempo de cada analisando, para que a análise não repita invasões nem abandonos traumáticos. O que não pode se expressar por palavras pode estar relacionado com aspectos cindidos que retornam no sensório, em atos ou no corpo. 
O que me refiro é como escutar o silêncio, se é um silêncio de uma repetiçãoreprodução, que remete ao desligado pulsional, silêncio mortífero? Ou um silêncio como um protesto à invasão do objeto? Ou ainda um silêncio protetor de uma intimidade ameaçada pelo poder do objeto? Entre o dito e o não dito, entre o representado, recalcado ou o indizível, carente de representação, que não pode se transformar em pensamento, como interpretar o silêncio? Nestes momentos, mais do que escutar, é necessário auscultar, como se ausculta um corpo quando se ouvem os ruídos do interior do coração, dos pulmões e das vísceras.

É difícil decidir qual o tempo de espera, manter a capacidade negativa, o tempo do não saber, para que o novo não seja apenas, de novo, o mesmo. Nas pequenas diferenças, nos interstícios dos pequenos gestos, muitas vezes, como um soslaio de olhar como guia, surge uma intervenção que gera uma distensão, e a sessão prossegue.

Com cada analisando temos que criar uma forma de nos comunicarmos, de construirmos a interação. Enfrentar os silêncios, para que se tornem um silêncio a dois, onde a angústia do não poder falar, se transforme em um ato preparatório para o sonho.

Quando as vivências de uma análise fazem sentido, elas permitem ao indivíduo apropriar-se de algo verdadeiramente seu, e é nesta experiência única que reside sua força. "Se, depois dessa volta para dentro, desse ensimesmar-se, brotarem versos, não mais pensará em perguntar, seja a quem for, se são bons" (Rilke, 2001, p. 24).

O processo analítico não é um continuum, não é linear. Ele é um caminho percorrido pela dupla analista-analisando, para que surjam novas representações que deem conta do sofrimento psíquico daqueles que depositam na análise a esperança de novas perspectivas para si. É construir narrativas que dêem sentido aos acontecimentos e à possibilidade de restituir identidades e de reconstruir laços, através do resgate das palavras e do simbólico rompido pela invasão do real. As palavras são a forma privilegiada de comunicação dos afetos e de ligação da energia pulsional. "As palavras são símbolos para memórias partilhadas" (Borges, 2000, p. 122).

$\mathrm{Na}$ clínica, defrontamo-nos com os aspectos neuróticos e não neuróticos dos analisandos. Na neurose, é o passado que não toma o seu lugar; nos pacientes não 
neuróticos, é quando o passado não se faz. A análise é uma reordenação do tempo, e as temporalidades se apresentam sob diferentes formas no processo analítico. Nesta perspectiva, retomo a noção de trauma entendido como um excesso que não pode ser processado pelo psiquismo, de uma marca que permaneceu como impressão ou traço e não se transformou em representação.

Poder narrar é transformar o traumático em capital psíquico. "Historiar é ligar, dar significado. É a forma de enfrentar o tempo coagulado do trauma; é torná-lo representável, nomeado, inserido no tempo histórico do sujeito. A construção de uma narrativa gera sentido; ela reconstitui a ideia de passado e presente, e abertura para o futuro. Um futuro sempre com múltiplas possibilidades” (Terra Machado, 2015, p. 59).

Freud postulou muitas definições para o aparelho mental, desde aparelho de linguagem, nas Afasias (1891); aparelho neuronal, no Projeto (1895); aparelho de memória, na Carta 52 (1896); até aparelho psíquico, em A Interpretação dos Sonhos (1900). Considero que, na psicanálise contemporânea, com todas as suas múltiplas possibilidades de aplicação e abrangência, podemos também nomear o aparelho psíquico como um aparelho de ligação (Bindung), no sentido que este termo pode assumir com seus diversos significados: Ligação, vínculo e laço (Hanns, 1996).

Em termos amplos, Bindung é o que produz ligações entre as pulsões e as representações, mas também se expande para o vínculo com o analista e com o laço social. A função analítica pode ser concebida como um trabalho de Eros, ainda que este trabalho inclua desconstruções e rupturas com o fixado psiquicamente, que também é uma das acepções de Bindung, encontradas no texto freudiano (Hanns, 1996).

“Os afetos buscam palavras” (Gutfreind, 2016, p. 63) e, no início, é assim mesmo: os afetos precisam ser nomeados, e são os investimentos iniciais que irão constituir nosso narcisismo, nosso sentimento de si, nossos ideais e nossa autoestima. Do excesso à falta, o amor é determinante.

A demanda de análise é uma demanda de amor e reconhecimento. Em uma "sessão de quarta-feira”, em janeiro de 1907, Freud ressalta: “[...] Compelimos o paciente a renunciar às suas resistências por amor a nós. Nossos tratamentos são tratamentos pelo 
amor”. Neste sentido, o que a análise produz são novas possibilidades de ligação, ainda que, para que se superem identificações alienantes, seja preciso romper com antigas formas de pensar e agir, ou seja, fixações que denunciam o traumático das vivências infantis. Temos que ter presente que a importância dos fatos não está no que efetivamente aconteceu, mas no destino que damos a eles. Nesse percurso, nesta travessia angustiante, de desconstruções e construções, de enfrentamento com o traumático inerente a cada caso, é preciso que o analisando se sinta acompanhado e que possa ter a confiança no vínculo, no genuíno interesse do analista no que está sendo comunicado.

Considero que é a disponibilidade de escuta e o investimento libidinal que asseguram o retorno de um analisando. Um psicanalista precisa trabalhar com o entusiasmo e a capacidade de se surpreender de um iniciante, fazendo com que, com cada novo analisando, a psicanálise renasça, parafraseando Guimarães Rosa, quando diz: "Um menino nasceu, o mundo tornou a começar".

\section{Avanços e aberturas para o social}

Toda clínica, nas mais diversas montagens da subjetividade, se depara, com uma dimensão do desamparo. Hoje, nossa clínica se expandiu para fora dos domínios dos consultórios. A escuta e o pensamento psicanalítico estão presentes nos hospitais, nas instituições de assistência social, varas judiciais, nas escolas, em diferentes âmbitos. Ela pode ser individual, com famílias, em grupo, enfim, são muitas as possibilidades de trabalho de um psicanalista. Esta diversidade da clínica oxigena a psicanálise.

Cada época e cada cultura têm suas coordenadas discursivas, seus valores e ideais, e a própria noção de patologia precisa ser compreendida dentro de um contexto histórico. Vivemos tempos conturbados e instáveis, com um panorama marcado pela polarização. Diante da ameaça de retrocesso, porém, surge algo novo - ou, se não é novo, temos que pensar em algo que era oculto e, agora, se apresenta no cotidiano. Refiro-me às manifestações da sexualidade com suas diversas formas de expressão que pedem passagem à visibilidade e reivindicam um lugar no social. Esta condição que põe em xeque os modelos binários se apresenta na clínica e faz trabalhar os conceitos da psicanálise, produzindo questionamentos e aberturas que estão além da psicopatologia e 
ainda é carente de teorizações. Embora tenha alcançado um maior espaço de debate e reflexão, esta situação dos que ousam romper com os modelos convencionais da sexualidade, ainda gera perplexidade, protestos e violência.

É intrínseco às nossas teorias considerar os reflexos da cultura na montagem da subjetividade e nas formas de sofrimento impingidas pelo social. Esta dimensão insere a ação do psicanalista no laço social. Sabemos que toda e qualquer exclusão é geradora de traumas que ganham uma proporção ainda mais intensa entre nós pelos atavismos de nosso contex to histórico. A negligência com o envolvimento em situações sociopolíticas cobra o seu preço e a atualidade têm mostrado os reflexos desta condição. A compreensão da dinâmica dos traumas cumulativos, precoces ou, ainda, de situações atuais que reeditam situações traumáticas, pode ser um caminho para pensarmos sobre a virulência do momento atual e também sobre as incongruências do passado.

O primeiro passo para que se possa ter alguma ação transformadora é admitir a existência de uma situação. Aquilo que não é falado e exposto permanece como um trauma que, embora mudo, produz efeitos.

A psicanálise pode contribuir para que se estabeleçam estratégias e ações para não sucumbirmos a um isolamento alienante do que nos cerca. Nós, psicanalistas, estamos convocados a somar esforços para mitigar a violência e a dor, para tentar reduzir o abismo entre os inseridos no social - os "bem nascidos" - e os invisíveis, os abjetos, que parecem só ser percebidos pelo avesso, quando cometem alguma violência. Resgatar memórias, construir sentido e conferir um lugar na história aos excluídos do social é um trabalho psicanalítico.

Ações importantes já vêm sendo feitas, e as instituições psicanalíticas têm dado ênfase ao trabalho social. Esta abertura é um avanço de nosso trabalho. Transpor as fronteiras da clínica privada e nos inserirmos mais diretamente no coletivo são formas de legitimar a clínica que é dirigida desde sempre para o ser humano.

O processo analítico implica libertação de limitantes formas de viver. A ampliação das capacidades mentais visa a uma emancipação psíquica, onde são criadas novas possibilidades de vida que, embora tolerando a falta e a incompletude, permitem ao 
sujeito estar inserido no social com a liberdade para agir e para não agir, de acordo com os princípios éticos da alteridade, da não indiferença para com a diferença do outro. $\mathrm{Na}$ análise, podemos resgatar a capacidade de sonhar, de devanear e fantasiar com os pés fincados na realidade. Concordo com Castoriadis (1992), quando ele afirma que a psicanálise não ensina o sentido da vida, mas ela pode sim, auxiliar que cada um encontre, invente e crie ele mesmo o seu próprio sentido.

\section{Referências}

Baranger, W.; Baranger, M.; Mom, J. M. (1987) "El trauma psíquico infantil, de nosotros a Freud: Trauma puro, retroactividad y reconstruccion". Revista de Psicoanálisis, Asociación Psicoanalítica Argentina, v. 44, n. 4, p. 745-774.

Borges, J. L. (2000). Esse ofício do verso. São Paulo, Companhia das Letras.

Busch, F. (2015). "Nosso ofício vital”. Revista Brasileira de Psicanálise, v. 49, n. 1, p. 99-118.

Castoriadis, C. (1992). "Psicanálise e projeto de autonomia". Revista do CEPdePA, n. 1, p. 101-112.

Francischelli, L. (2012). "Psicanalisar hoje: algumas reflexões". Revista Brasileira de Psicanálise. São Paulo, v. 46, n. 1, p. 52-66.

Freud, S. (1913/1969). "Sobre o início do tratamento". In: completas. Rio de Janeiro, Imago. (Edição Standard Brasileira, 12).

Freud, S. (1920/1969). “Além do princípio do prazer”. In: completas. Rio de Janeiro. Imago. (Edição Standard Brasileira, 18). Obras psicológicas

Freud, S. (1923/1969). "Dois verbetes de enciclopédia". In: completas. Rio de Janeiro, Imago. (Edição Standard Brasileira, 18). Obras psicológicas

Green, A. (2008). Orientações para uma psicanálise contemporânea. Rio de Janeiro, Imago/ São Paulo, SBPSP/Depto. de Publicações.

Gutfreind, C. (2016). Crônica dos afetos: a psicanálise no cotidiano. Porto Alegre, Artmed.

Hanns, L. A. (1996). Dicionário comentado do alemão de Freud. Rio de Janeiro, Imago.

Hartke, R. (2018). Comentário na Reunião Científica da SPPA, na apresentação do trabalho pré-publicado do Congresso da Fepal "Masoquismo: destino das pulsões origem do sujeito", de Ana Paula Terra Machado e Ignácio Paim Filho.

Melville, E, H. (2014). O escrevente. São Paulo. Grua.

Rilke, R. M. (2001). Cartas e a um jovem poeta. 32. ed. São Paulo. Globo.

Schafer, R. (1990). "The search for common ground”. International Journal of Psychoanalysis. v. 71, p. 49-52.

Terra Machado, A. P. (2015). "O mundo em mutação: realidades e ficções". Bergasse 19. Revista da Sociedade Brasileira de Psicanálise de Ribeirão Preto, v. 6, n. 1, p. 53-61. 